\title{
Developing an OMERACT Core Outcome Set for Assessing Safety Components in Rheumatology Trials: The OMERACT Safety Working Group
}

\author{
Louise Klokker, Peter Tugwell, Daniel E. Furst, Dan Devoe, Paula Williamson, Caroline B. Terwee, \\ Maria E. Suarez-Almazor, Vibeke Strand, Thasia Woodworth, Amye L. Leong, Niti Goel, \\ Maarten Boers, Peter M. Brooks, Lee S. Simon, and Robin Christensen
}

ABSTRACT. Objective. Failure to report harmful outcomes in clinical research can introduce bias favoring a potentially harmful intervention. While core outcome sets (COS) are available for benefits in randomized controlled trials in many rheumatic conditions, less attention has been paid to safety in such COS. The Outcome Measures in Rheumatology (OMERACT) Filter 2.0 emphasizes the importance of measuring harms. The Safety Working Group was reestablished at the OMERACT 2016 with the objective to develop a COS for assessing safety components in trials across rheumatologic conditions.

Methods. The safety issue has previously been discussed at OMERACT, but without a consistent approach to ensure harms were included in COS. Our methods include (1) identifying harmful outcomes in trials of interventions studied in patients with rheumatic diseases by a systematic literature review, (2) identifying components of safety that should be measured in such trials by use of a patient-driven approach including qualitative data collection and statistical organization of data, and (3) developing a COS through consensus processes including everyone involved.

Results. Members of OMERACT including patients, clinicians, researchers, methodologists, and industry representatives reached consensus on the need to continue the efforts on developing a COS for safety in rheumatology trials. There was a general agreement about the need to identify safety-related outcomes that are meaningful to patients, framed in terms that patients consider relevant so that they will be able to make informed decisions.

Conclusion. The OMERACT Safety Working Group will advance the work previously done within OMERACT using a new patient-driven approach. (First Release October 15 2016; J Rheumatol 2017;44:1916-19; doi:10.3899/jrheum.161105)

Key Indexing Terms:

CORE OUTCOME SET HARM SAFETY RHEUMATOLOGY OMERACT

\begin{abstract}
From the Musculoskeletal Statistics Unit, The Parker Institute, Bispebjerg and Frederiksberg Hospital, Copenhagen, Denmark; Department of Medicine, School of Epidemiology, Public Health and Community Medicine, University of Ottawa, Ottawa, Ontario; Department of Medicine, University of Calgary, Cumming School of Medicine, Calgary, Alberta, Canada; Section of Rheumatology and Clinical Immunology, University of Texas MD Anderson Cancer Center, Houston, Texas; Division of Immunology and Rheumatology, Stanford University, Stanford, California; David Geffen School of Medicine, Division of Rheumatology, University of California at Los Angeles (UCLA); Healthy Motivation, and Global Alliance for Musculoskeletal Health, Bone and Joint Decade, Santa Barbara, California; Strategic Drug Development, Advisory Services, Quintiles and Division of Rheumatology, Duke University School of Medicine, Durham, North Carolina; SDG LLC, Cambridge, Massachusetts, USA; Institute of Translational Medicine, University of Liverpool, Liverpool, UK; Department of Epidemiology and Biostatistics and the EMGO Institute for Health and Care Research, Amsterdam; Department of Epidemiology and Biostatistics, Amsterdam Rheumatology and Immunology Center, VU University Medical Center, Amsterdam, the Netherlands; Centre for Health Policy Melbourne School of Population and Global Health, University of Melbourne, Australia.
\end{abstract}

As part of the supplement series OMERACT 13, this report was reviewed internally and approved by the Guest Editors for integrity, accuracy, and consistency with scientific and ethical standards.

L. Klokker, PT, MSc, PhD Fellow, Clinical Epidemiology, Musculoskeletal Statistics Unit, The Parker Institute, Bispebjerg and Frederiksberg

\begin{abstract}
Hospital; P. Tugwell, OC, LRCP, MRCS, MD, MSc, FRCPS, FRCP(UK), FCAHS, Canada Research Chair in Health Equity, Department of Medicine, School of Epidemiology, Public Health and Community Medicine, University of Ottawa; D.E. Furst, MD, David Geffen School of Medicine, Division of Rheumatology, UCLA; D. Devoe, BA, MSc, PhD Student, Research Associate, Health Services Research, Department of Medicine, University of Calgary, Cumming School of Medicine; P. Williamson, MSc, PhD, Professor of Medical Statistics, Institute of Translational Medicine, University of Liverpool; C.B. Terwee, PhD, Associate Professor, Department of Epidemiology and Biostatistics and the EMGO Institute for Health and Care Research, VU University Medical Center; M.E. Suarez-Almazor, MD, PhD, Barnts Family Distinguished Professor, Section of Rheumatology and Clinical Immunology, University of Texas MD Anderson Cancer Center; V. Strand, MD, Adjunct Clinical Professor, Division of Immunology and Rheumatology, Stanford University, and Healthy Motivation; T. Woodworth, MD, David Geffen School of Medicine, Division of Rheumatology, UCLA; A.L. Leong, MBA, President and CEO, Healthy Motivation, and Director of Strategic Relations, Global Alliance for Musculoskeletal Health, Bone and Joint Decade; N. Goel, MD, Vice President, Strategic Drug Development, Advisory Services, Quintiles and Adjunct Assistant Professor, Division of Rheumatology, Duke University School of Medicine; M. Boers, MSc, MD, PhD, Professor of Clinical Epidemiology, Department of Epidemiology and Biostatistics, Amsterdam Rheumatology and Immunology Center, VU University Medical Center; P.M. Brooks, MD, FRACP Honorary Professor Fellow, Centre for Health Policy Melbourne School of Population and Global Health University of Melbourne; L.S. Simon, MD,
\end{abstract}


SDG LLC; R. Christensen, BSc, MSc, PhD, Head of Unit, Professor of Clinical Epidemiology, Musculoskeletal Statistics Unit, The Parker Institute, Bispebjerg and Frederiksberg Hospital.

Address correspondence to Dr. R. Christensen, Musculoskeletal Statistics

Unit, The Parker Institute, Bispebjerg og Frederiksberg Hospital,

Copenhagen,Denmark.E-mail:Robin.Christensen@regionh.dk

This Safety Working Group within the Outcome Measures in Rheumatology (OMERACT) 1,2,3,4,5,6 was reestablished at OMERACT 2016 to develop a core outcome set (COS) for assessing safety components in rheumatology trials using an evidence-based, consensus-driven standard definition of safety in patients with rheumatic diseases.

Because every healthcare intervention carries some risk of harm, clinical decision making needs to be supported by a systematic assessment of the balance of harm compared with the apparent benefit. For example, a systematic review that considers only the favorable outcomes of an intervention, without also assessing the adverse effects, can mislead by introducing a bias favoring the intervention ${ }^{7}$. It is critical that all patient-important outcomes are measured and subsequently reported, either directly in a journal article or as an elaborately detailed supplementary file.

Currently there is a large and disturbing amount of literature indicating a general failure in the quality of reporting health research ${ }^{8}$. According to Moher, et al, many publications lack clarity, transparency, and completeness in how the authors actually carried out their research ${ }^{8}$. To counterbalance that, internationally recognized reporting guidelines now exist for a diversity of research areas with different study designs; the Enhancing the QUAlity and Transparency Of health Research (www.equator-network.org) is an international initiative that seeks to improve the reliability and value of biomedical research literature by promoting the transparent and accurate reporting of studies ${ }^{9}$.

Members of the Consolidated Standards of Reporting Trials group have highlighted that the reporting of harms in randomized controlled trials (RCT) has received less attention than reporting of benefit, and the data available are often inadequate ${ }^{10}$. As a consequence, many trials that are published do not add value in clinical decision making because of fundamental flaws in reporting. Both scientific evidence and ethical necessity call for action to improve the quality of reporting of harms ${ }^{10}$.

There is strong international advocacy to shift the research model through developing COS across all disease areas that always include the assessment of both benefits and harms. Initiatives such as OMERACT ${ }^{11,12}$ and the Core Outcome Measures in Effectiveness Trials ${ }^{13}$ have demonstrated that COS improve the reporting of trial outcomes. The Cochrane Musculoskeletal systematic reviews routinely include core sets that state both benefits and harms in summary of findings tables ${ }^{14}$.

There is currently a focus on COS for assessing benefit in rheumatology trials; however, none have been developed to address safety components. The aim of the Safety Working Group was to address this need. Specific objectives were to (1) identify harmful outcomes in trials of diverse interventions evaluated in patients with rheumatic diseases, (2) identify components of safety that should be measured in trials in rheumatic diseases, and (3) develop a COS for safety in RCT in rheumatology. The COS should allow results of trials to be compared and combined and thus will contribute usable information for clinical decision making ${ }^{15}$.

The main contribution of our paper was the consensus obtained among leading (experienced) members of OMERACT, including patients, clinicians, researchers, methodologists, and industry representatives, that there was a need to continue the efforts to develop a COS for safety in rheumatology trials. This will advance the work previously done and published in previous publications within OMERACT ${ }^{1,2,3,4,5,6}$ using a new patient-driven approach.

\section{Assembly of Working Group and Work Plan}

The Safety Working Group follows the OMERACT Master Checklist for developing core outcome measurement sets as described in The OMERACT Handbook ${ }^{16}$. Adherence to the checklist items at this early stage of the process is described.

Forming an OMERACT working group and review of domain and instruments previously used. Following the approval of the OMERACT Filter $2.0^{12}$, it was decided that OMERACT needed to establish consensus on the safety domains and instruments included in OMERACT COS. At OMERACT 2016, the Safety Working Group (previously called the Drug Safety Working Group, but now the mandate has been broadened to all types of interventions), as part of its research agenda, determined as its goal to develop a COS for assessing safety components in rheumatology - derived primarily from patients with rheumatic diseases ${ }^{12}$.

At OMERACT 3 (in 1996), the Toxicity Working Group was formed with the purpose of developing an adverse event assessment tool for the use in rheumatology clinical trials to improve consistency in reporting ${ }^{1}$. Through a literature review, existing tools were identified. One of these was the World Health Organization Common Toxicity Criteria (CTC) on which it was decided to build the Rheumatology CTC (RCTC) at OMERACT 5 in 2000. Following discussions at OMERACT 6 in 2002, it was decided to develop 2 tools, building on the $\mathrm{RCTC}^{1}$, the Stanford Toxicity Index ${ }^{17}$, the symptom list from the complete Health Assessment Questionnaire ${ }^{18}$, the Patient Self-Report Adverse Event Instrument, and the Investigator Report Adverse Event instrument ${ }^{19}$. These instruments were presented at OMERACT 7 in 2004, where the discussion included the advantages of electronic instrument versions and a "more patient-friendly system than the medical body systems approach"3. A second version of the RCTC was published following discussion and revision at OMERACT 8 in $2006^{2}$.

$$
\text { Personal non-commercial use only. The Journal of Rheumatology Copyright @ } 2017 \text {. All rights reserved. }
$$


At OMERACT 9 in 2008, the OMERACT Executive brought together clinical trialists, pharmacoepidemiologists, clinicians, clinical epidemiologists, statistical experts, and regulatory representatives to discuss different approaches to define risk and perhaps improved ways to express it ${ }^{4,5}$. One idea was the development of a single metric to assess both benefit and risk, a challenge that led to the development of a simple instrument to assess both benefit and harm in clinical trials $^{6}$. The instrument proved to be feasible, but should be further developed in the context of the OMERACT initiative, including more elaborate work on what constructs were being measured. Thus, an obvious starting point would be to create a clear definition of the construct of interest (safety) embedded in a conceptual model (according to the OMERACT filter 2.0).

Groups involved and their contacts identified. The development of the working group will involve multiple key groups to ensure that a COS is suitable and well accepted in future research. Patients, clinical researchers, health professionals, methodologists, policymakers, and industry representatives will be included, and they will represent at least 3 continents (Europe, North America, and Australia).

Implementation of Delphi and/or focus groups. Consultations will be conducted to ensure content and face validity of the domains potentially included in the COS. The method applied will be concept mapping ${ }^{20,21}$, a structured group conceptualization process combining the qualitative approach of focus group/survey processes and statistical analyses to support the structuring of data, as described by Kane and Trochim ${ }^{22}$. Anticipated sample size for patient focus groups is 20 , and for surveys including others, 200 . One significant advantage of this concept mapping approach is that participants handle the first step of the data analysis, i.e., the organization of themes. This might provide a solution to the issue of developing a "more patient-friendly system than the medical body systems approach" that was called for at OMERACT $7^{3}$.

The input will contribute to the pool of safety components identified through review of the literature, and allow an organization of data building on the perspectives of the patients. The consensus process will be done "the OMERACT way," including Delphi surveys, discussions, and plenary sessions at OMERACT meetings ${ }^{23}$. It is an iterative process with the goal to develop a COS that everyone involved can accept.

\section{Core Domain Set Selection}

Definition of context: setting (scope). Based on current and previous OMERACT discussions, the scope of the core set is safety components in rheumatology clinical trials. Specification of the scope is expected following discussions in the working group based on the PICO structure, defining the patients/population, intervention, comparator/control, and outcome.

\section{REFERENCES}

1. Woodworth TG, Furst DE, Strand V, Kempeni J, Fenner H, Lau CS, et al. Standardizing assessment of adverse effects in rheumatology clinical trials. Status of OMERACT Toxicity Working Group March 2000: towards a common understanding of comparative toxicity/safety profiles for antirheumatic therapies. J Rheumatol 2001;28:1163-9

2. Woodworth T, Furst DE, Alten R, Bingham CO 3rd, Yocum D, Sloan V, et al. Standardizing assessment and reporting of adverse effects in rheumatology clinical trials II: the Rheumatology Common Toxicity Criteria v.2.0. J Rheumatol 2007;34:1401-14.

3. Lassere MN, Johnson KR, Boers M, Carlton K, Day RO, de Wit M, et al. Standardized assessment of adverse events in rheumatology clinical trials: summary of the OMERACT 7 drug safety module update. J Rheumatol 2005;32:2037-41.

4. Simon LS, Strand CV, Boers M, Brooks PM, Tugwell PS, Bombardier C, et al. How to ascertain drug safety in the context of benefit. Controversies and concerns. J Rheumatol 2009;36:2114-21.

5. Simon LS, Strand CV, Boers M, Brooks PM, Henry D, Tugwell PS. Observations from the OMERACT Drug Safety Summit, May 2008. J Rheumatol 2009;36:2110-3.

6. Boers M, Brooks P, Fries JF, Simon LS, Strand V, Tugwell P. A first step to assess harm and benefit in clinical trials in one scale. J Clin Epidemiol 2010;63:627-32.

7. Loke YK, Price D, Herxheimer A; Cochrane Adverse Effects Methods Group. Systematic reviews of adverse effects: framework for a structured approach. BMC Med Res Methodol 2007;7:32.

8. Moher D, Schulz KF, Simera I, Altman DG. Guidance for developers of health research reporting guidelines. PLoS Med 2010;7:e1000217.

9. Christensen R, Bliddal H, Henriksen M. Enhancing the reporting and transparency of rheumatology research: a guide to reporting guidelines. Arthritis Res Ther 2013;15:109.

10. Ioannidis JP, Evans SJ, Gøtzsche PC, O’Neill RT, Altman DG, Schulz K; CONSORT Group. Better reporting of harms in randomized trials: an extension of the CONSORT statement. Ann Intern Med 2004;141:781-8.

11. Boers M, Tugwell P. OMERACT conference questionnaire results. OMERACT Committee. J Rheumatol 1993;20:552-4.

12. Boers M, Kirwan JR, Wells G, Beaton D, Gossec L, d'Agostino MA, et al. Developing core outcome measurement sets for clinical trials: OMERACT filter 2.0. J Clin Epidemiol 2014;67:745-53.

13. Gorst SL, Gargon E, Clarke M, Blazeby JM, Altman DG, Williamson PR. Choosing important health outcomes for comparative effectiveness research: an updated review and user survey. PLoS One 2016;11:e0146444.

14. Ghogomu EA, Maxwell LJ, Buchbinder R, Rader T, Pardo J, Johnston RV, et al; Editorial Board of the Cochrane Musculoskeletal Group. Updated method guidelines for Cochrane Musculoskeletal Group systematic reviews and metaanalyses. J Rheumatol 2014;41:194-205.

15. Zorzela L, Loke YK, Ioannidis JP, Golder S, Santaguida P, Altman DG, et al; PRISMAHarms Group. PRISMA harms checklist: improving harms reporting in systematic reviews. BMJ 2016;352:i157.

16. Boers M, Kirwan JR, Tugwell P, Beaton D, Bingham CO III, Conaghan PG, et al. The OMERACT Handbook. [Internet. Accessed September 19, 2016.] Available from: www.omeract.org/pdf/OMERACT_Handbook.pdf

17. Fries JF, Spitz PW, Williams CA, Bloch DA, Singh G, Hubert HB A toxicity index for comparison of side effects among different drugs. Arthritis Rheum 1990;33:121-30.

18. Fries JF, Spitz P, Kraines RG, Holman HR. Measurement of patient outcome in arthritis. Arthritis Rheum 1980;23:137-45.

Personal non-commercial use only. The Journal of Rheumatology Copyright @ $\odot 2017$. All rights reserved 
19. Lassere MN, Johnson KR, Van Santen S, Carlton K, Rappo J, Michael R, et al. Generic patient self-report and investigator report instruments of therapeutic safety and tolerability. J Rheumatol 2005;32:2033-6.

20. Trochim W, Kane M. Concept mapping: an introduction to structured conceptualization in health care. Int J Qual Health Care 2005; 17:187-91.

21. Buchbinder R, Batterham R, Elsworth G, Dionne CE, Irvin E, Osborne RH. A validity-driven approach to the understanding of the personal and societal burden of low back pain: development of a conceptual and measurement model. Arthritis Res Ther 2011;13:R152.

22. Kane M, Trochim WM. Concept mapping for planning and evaluation. London: SAGE Publications Inc.; 2007.

23. Tugwell P, Boers M, d'Agostino MA, Beaton D, Boonen A, Bingham CO 3rd, et al. Updating the OMERACT filter: implications of filter 2.0 to select outcome instruments through assessment of "truth": content, face, and construct validity. J Rheumatol 2014;41:1000-4. 